\title{
Preparation of activated carbon from banana peel waste for reducing air pollutant from motorcycle muffler
}

\author{
Achmad Chafidz ${ }^{1, *}$, Widi Astuti ${ }^{2}$, Dhoni Hartanto $^{2}$, Aulia Septiani Mutia ${ }^{2}$, Purtiah Rantau Sari ${ }^{2}$ \\ ${ }^{1}$ Department of Chemical Engineering, Universitas Islam Indonesia, Yogyakarta 55584, Indonesia \\ ${ }^{2}$ Department of Chemical Engineering, Universitas Negeri Semarang, Semarang 50229, Indonesia
}

\begin{abstract}
The exhaust gas or emission from motor vehicle contains various pollutants and some of them are toxic and very harmful for human health. In the present work, we prepared an activated carbon to reduce the toxic pollutants (via adsorption process) from the exhaust gas of the motor vehicle (particularly motorcycle in this work). The activated carbon was prepared from local banana peel which considered as an agricultural waste without economic value. To prepare the activated carbon, banana peel was carbonized using furnace at $500^{\circ} \mathrm{C}$. Then the resulted carbon was activated using chemical activation with $\mathrm{ZnCl}_{2}$ and physical activation with either microwave $(300 \mathrm{~W})$ or furnace $\left(700^{\circ} \mathrm{C}\right)$. The prepared activated carbon was then characterized using Scanning Electron Microscope (SEM) and Fourier Transform Infrared (FT-IR) analysis. The SEM result showed that the pore of microwave induced $\mathrm{ZnCl}_{2}$ activated carbon $\left(\mathrm{AC}_{\mathrm{M}}\right)$ was larger than the pore of virgin char/carbon and furnace induced $\mathrm{ZnCl}_{2}$ activataed carbon $\left(\mathrm{AC} \mathrm{C}_{\mathrm{F}}\right)$. The FT-IR spectrum of $\mathrm{ACM}$ showed some peaks at $3408.59 \mathrm{~cm}^{-1}, 1589.25 \mathrm{~cm}^{-1}$, and $1093.63 \mathrm{~cm}^{-1}$. They are assigned to $\mathrm{O}-\mathrm{H}$ stretching, $\mathrm{C}=\mathrm{O}$ stretching, and $\mathrm{C}-\mathrm{OH}$ stretching. Additionally, the adsorption performance of the prepared activation carbon to reduce the pollutants concentration (i.e. $\mathrm{CO}$ and $\mathrm{CH}$ ) from the exhaust gas of motor vehicle was investigated. The results showed that the activated carbon induced by microwave and $\mathrm{ZnCl}_{2}$ activation $\left(\mathrm{AC}_{\mathrm{M}}\right)$ gave the best result. The adsorption or removal efficiency of gas CO reached approximately $97.64 \%$ vol.
\end{abstract}

\section{Introduction}

Nowdays, air pollution resulted from the exhaust emission of motor vehicle engine is a topic of concern, due to the significant number of motor vehicles in the world, especially in the big cities. Exhaust emission of motorcycle can contribute about 70-80 percent of air pollution. The exhaust gas or emission of motor vehicle contains various pollutants such as carbon monoxide $(\mathrm{CO})$, carbon dioxide $\left(\mathrm{CO}_{2}\right)$, hydrocarbon $(\mathrm{HC})$, nitrogen oxide $\left(\mathrm{NO}_{\mathrm{x}}\right)$, sulfur oxide $\left(\mathrm{SO}_{\mathrm{x}}\right)$, particulate, etc. Some of the pollutants are toxic and very harmful for human health. One of ways to reduce the air pollution is via adsorption process by using an activated carbon. Activated carbon is a porous material that behaves as a powerful adsorbent because of high surface area, adequate pore size distribution, and variable characteristics of surface chemistry, low ash content, and relatively high mechanical strength. The activated carbon are used in many application such as removal or adsorb of harmful gasses like $\mathrm{CO}$ and $\mathrm{HC}$ gas. The synthesis of activated carbon can be carried out through two step process that is carbonization and activation [1]. Activation step can be performed by physical or chemical process. In physical process, the precursor is heated at $700-1100^{\circ} \mathrm{C}$ in presence of oxidizing agents [1] while in chemical process, the precursor is reacted with chemical agent including $\mathrm{H}_{3} \mathrm{PO}_{4}$ [2], $\mathrm{KOH}[3]$ and $\mathrm{ZnCl}_{2}$ [4].
On the other hand, agricultural biomass waste is a renewable resource that can be further utilized to provide a broad range of useful chemicals, materials and energy, which have economic values [5]. Banana peel is one of agricultural biomass waste that has potential to be used as a raw material for the production of activated carbon [6]. It is because banana peel has high lignocellulose content, approximately $90.3 \%$ (dry weight based) [7]. Activated carbon can be prepared by chemical activation process using $\mathrm{ZnCl}_{2}$. The use of $\mathrm{ZnCl}_{2}$ as an activating reagent is because it can make high specific surface area [8]. After chemical activation, the next process is physical activation using heat either by using microwave or furnace. In term of microwave heating, the energy is freely transformed into heat inside the particles by ionic conduction and dipole rotation. The microwave induced reaction is more effective and faster than a conventional furnace [9].

\section{Experimental}

\subsection{Preparation of activated carbon}

Banana peels were collected as wastes from the local fruit markets in Semarang city, Indonesia. They were cut into small pieces of about $2 \mathrm{~cm} \times 2 \mathrm{~cm}$, washed with water to remove surface dirt then sun dried in 3 days and dried

\footnotetext{
* Corresponding author: achmad.chafidz@uii.ac.id
} 
using oven at $110^{\circ} \mathrm{C}$ until the weight is constant. The dried banana peels were then crushed into powder form. The powdered banana peel was then carbonized using furnace at $500^{\circ} \mathrm{C}$ for 1 hour. The carbonized material (char) was soaked in zink chloride $\left(\mathrm{ZnCl}_{2}\right)$ solution with an impregnation ratio $\left(\mathrm{ZnCl}_{2}\right.$ :char) of $3: 1(\mathrm{w} / \mathrm{w})$ in $10 \mathrm{ml}$ aquades for 14 hours and then dehydrated in an oven at $110^{\circ} \mathrm{C}$ for 6 hours. The sample was then physically activated using either microwave and furnace. The sample that was activated by microwave (called $\mathrm{AC}_{\mathrm{M}}$ ) was heated at $300 \mathrm{~W}$ for $5 \mathrm{~min}$. Whereas, the sample that was activated by furnace (called $\mathrm{AC}_{\mathrm{F}}$ ) was heated at $700^{\circ} \mathrm{C}$ for 1 hour. The resulted activated carbon (AC) were washed with $\mathrm{HCl} 0.2 \mathrm{~N}$ after cooling to dissolve and remove any residual ash, and subsequently followed by washing with hot distillled water until $\mathrm{pH}$ reached 7.0. Finally, the activated carbons were dried in an oven at $110^{\circ} \mathrm{C}$ until the weight is constant. In summary, there will be three samples of activated carbon, which are: banana peel char/carbon (without activation), activated carbon by microwave $\left(\mathrm{AC}_{\mathrm{M}}\right)$, and activated carbon by furnace $(\mathrm{AC})$.

\subsection{Characterization of activated carbon}

The morphology of char and activated carbon (i.e. $\mathrm{AC}_{\mathrm{M}}$ and $\mathrm{AC}_{\mathrm{F}}$ ) were investigated by scanning electron microscope (SEM). Then the functional groups present in the raw material (banana peel), $\mathrm{AC}_{\mathrm{M}}$ before and after gas emission adsorption of motor vehicle were evaluated from Fourier Transform Infrared Spectrophotometer (FT-IR) spectra, which were recorded between 4000 and $450 \mathrm{~cm}^{-}$

\subsection{Muffler design and adsorption test}

The performance of three activated carbon samples (i.e. char/without activation, $\mathrm{AC}_{\mathrm{M}}$, and $\mathrm{AC}_{\mathrm{F}}$ ) was measured by analyzing the exhaust emission from the motorcycle muffler by using gas analyzer, STARGAS 898 (Tecnotest, Italy). The motorcycle used in this work was a 4-stroke engine motorcycle, Mio brand 2012 (Honda, Indonesia). Prior to the tests, the samples were put inside the motorcycle muffler, as shown in Figure 1. The muffler used in this study has a little different design than the muffler in general. In this study, each of the activated carbon samples with a weight of $10 \mathrm{~g}$ was placed in an adsorbent holder/container made of stainless steel tube with $5 \mathrm{~cm}$ long and diameter fit to the channel of muffler. The stainless steel material was selected due to its superior corrosion resistance. The adsorbent container was placed on the channel after the gas discharge from the engine. At both ends of the tube were closed with a mesh (i.e. $150 \mathrm{mesh}$ ), so that the activated carbon granular will not come out of the adsorbent tube due to the high pressure of the exhaust gas. The muffler design with the adsorbent (i.e. activated carbon) container is presented in Fig. 1.

The working principles of the test are as follow: First, the exhaust gas from the combustion process of the motor engine enters into the adsorbent tube. Then the gas makes a contact with both carbon/char (without activation) and the activated carbon (either $\mathrm{AC}_{\mathrm{M}}$ or $\mathrm{AC} \mathrm{C}_{\mathrm{F}}$ ), and subsequently the gas pollutants (e.g. $\mathrm{CO}$ and $\mathrm{CH}$ ) are absorbed by the activated carbon. Expectedly, the gas coming out of the adsorbent tube has low $\mathrm{CO}$ and $\mathrm{HC}$ gas concentration, and then flows into the exhaust drain and

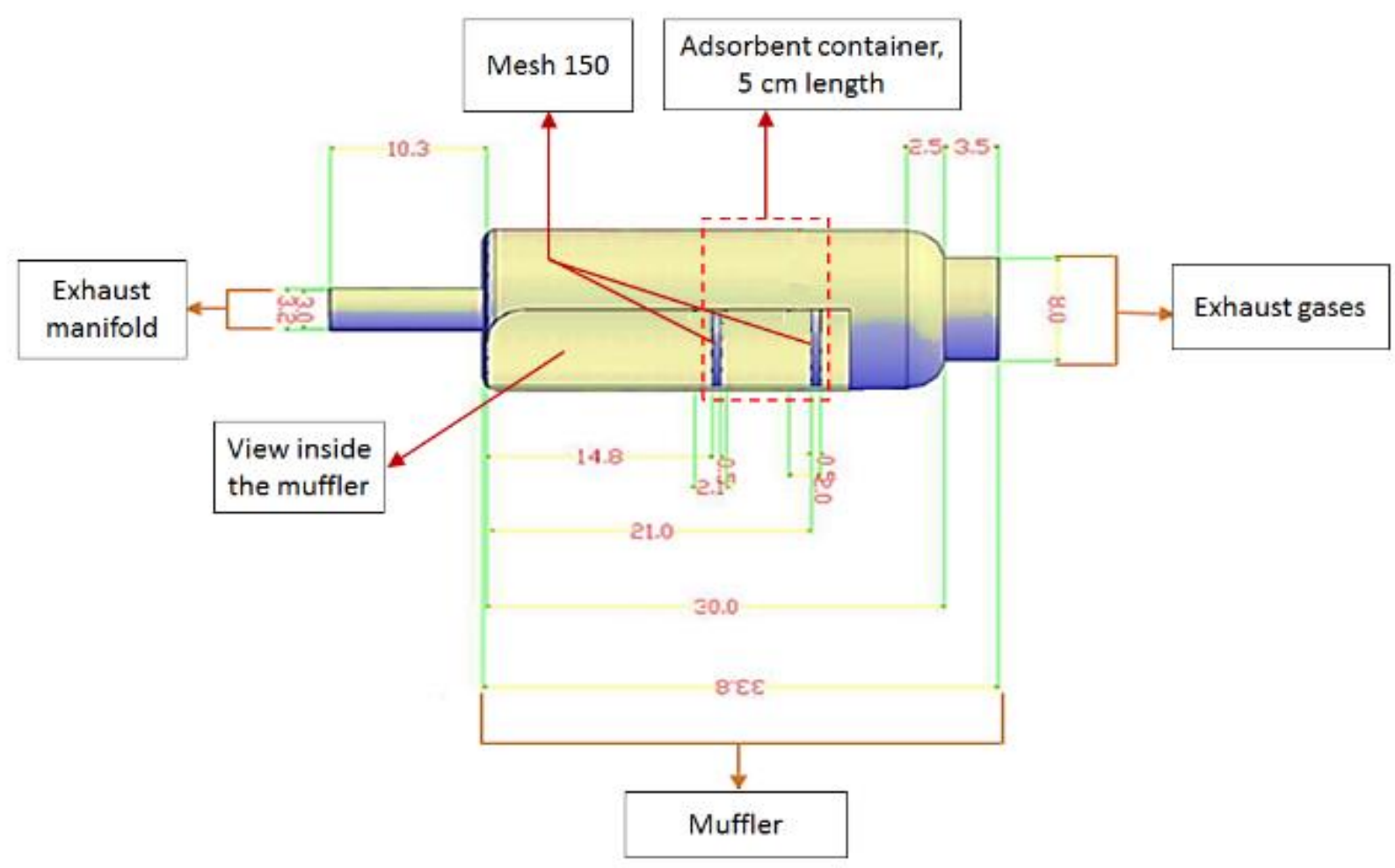

Fig. 1. Muffler design used for the gas emission test 
released to the environment. The muffler has a simple design, because it can be dismantled and the activated carbon on the tube adsorbent can be easily replaced when it is saturated. Additionally, this design is also cheap, because the adsorbent tube used is not too long and thus, only need small amount of adsorbent/activated carbon. From this test results, the adsorption efficiency of each activated carbon samples were then compared to determine the best activated carbon in reducing gas pollutant (i.e. $\mathrm{CO}$ and $\mathrm{HC}$ ) in the gas emission of motorcycle.

\section{Results and discussion}

\subsection{Morphological analysis}

Scanning electron microscopy (SEM) technique was used to observe the surface morphology of the activated carbon samples. The surface morphology of char (carbon without activation), $\mathrm{AC}_{\mathrm{M}}$, and $\mathrm{AC}_{\mathrm{F}}$ were evaluated by the $\mathrm{SEM}$ at 1000X magnification and the obtained images are shown in Fig. 2.
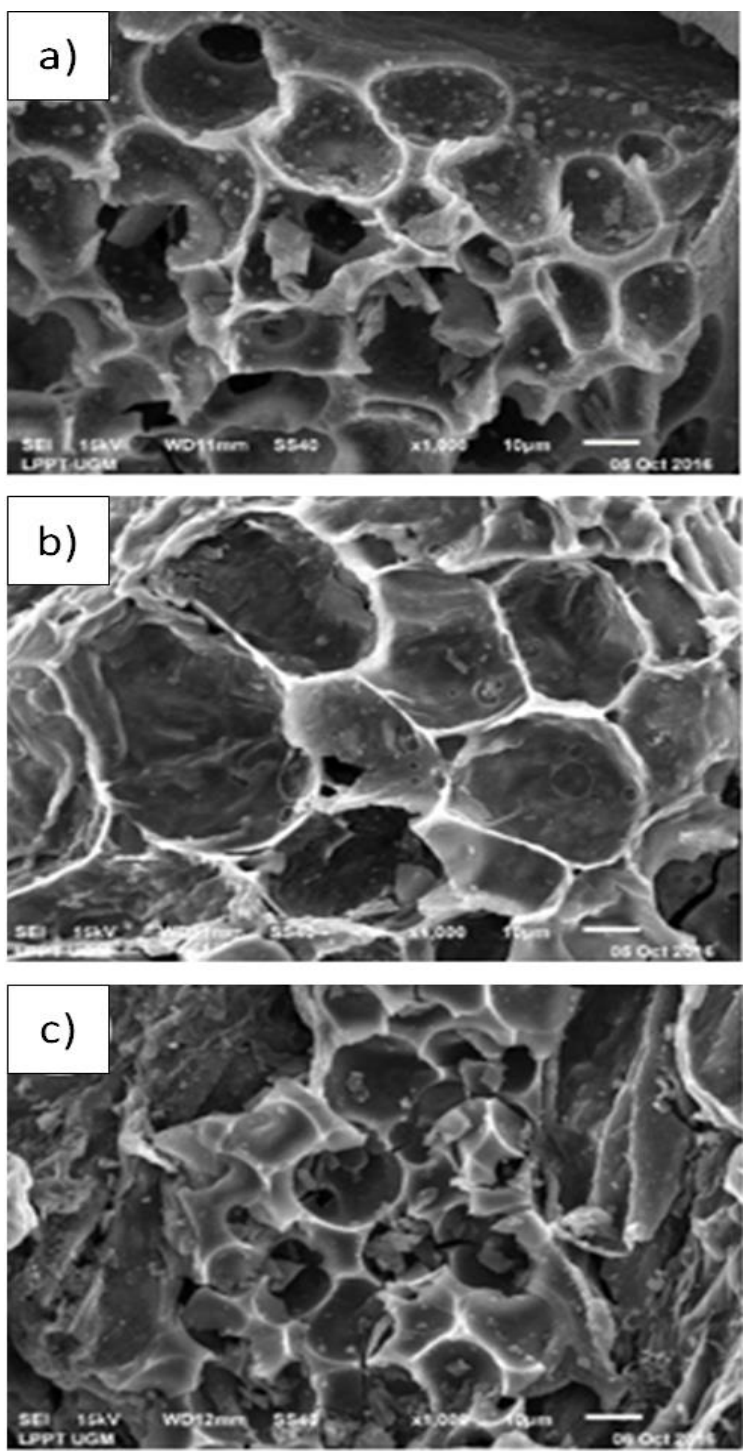

Fig. 2. SEM micrograph of (a) Char; (b) $A_{C}$; and (c) $A_{C}$.

\subsection{Fourier Transform InfraRed (FT-IR) analysis}

The FT-IR analysis was carried out to determine the availability of functional groups. Functional group analysis was performed on banana peel carbon powder (i.e. char); $\mathrm{ZnCl}_{2}$ activated carbon and microwave $\left(\mathrm{AC}_{\mathrm{M}}\right)$, the $\mathrm{AC}_{\mathrm{M}}$ before and after adsorption test. The functional group analysis was performed at wavelength range of $4000-370 \mathrm{~cm}-1$. The FT-IR test results of banana peel carbon/char and banana peel based activated carbon (i.e. $\mathrm{AC}_{\mathrm{M}}$ ) are presented in Fig. 3. Whereas, the FT-IR test results of $\mathrm{ACM}_{\mathrm{M}}$ before and after the adsorption are depicted in Fig. 4.

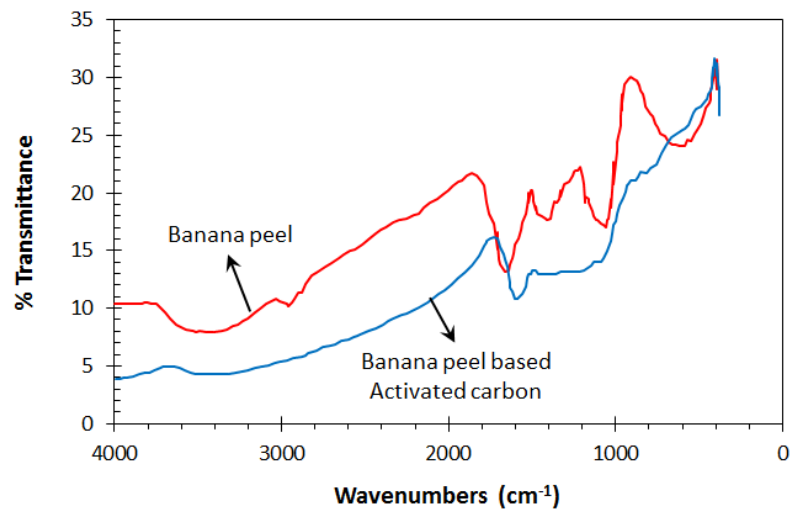

Fig. 3. FT-IR spectrums of banana peel and banana peel carbon based activated carbon by $\mathrm{ZnCl}_{2}+$ Microwave (i.e. $\mathrm{AC}_{\mathrm{M}}$ )

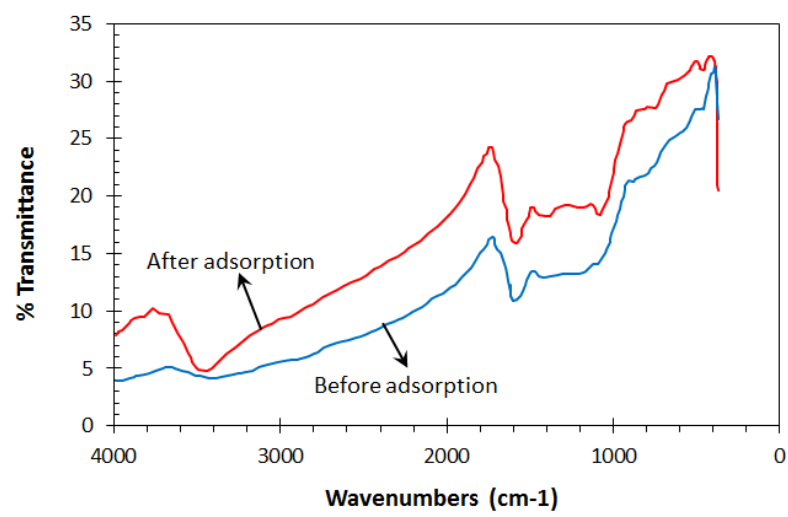

Fig. 4. FT-IR spectrums of banana peel carbon based activated carbon by $\mathrm{ZnCl}_{2}+$ Microwave (i.e. $\mathrm{ACM}$ ); before and after the adsorption tests

As seen in Fig. 3, the banana peel spectra shows the absorption peak at $3430.59 \mathrm{~cm}^{-1}$ indicating the presence of an O-H functional group [11]. The absorption peak at $1642.28 \mathrm{~cm}^{-1}$ shows the presence of $\mathrm{C}=\mathrm{C}$ groups of aromatic compounds [11]. While the presence of C-O-C of an ether group was indicated by uptake of $1037.03 \mathrm{~cm}^{-}$ ${ }^{1}$ [11]. The peak at $577 \mathrm{~cm}^{-1}$ wavelength indicates the presence of an $\mathrm{C}-\mathrm{H}$ group. Whereas, for the spectra of banana peel based activated carbon which activated using $\mathrm{ZnCl}_{2}$ and microwave (i.e. $\mathrm{AC}_{\mathrm{M}}$ ) shows an absorption peak at $3408.59 \mathrm{~cm}^{-1}$ indicating the presence of $\mathrm{O}-\mathrm{H}$ group which may contain water, alcohol and phenol components [11]. The absorption peak at $1589.25 \mathrm{~cm}^{-1}$ shows the presence of $\mathrm{C}=\mathrm{C}$ groups of aromatic compounds, while the $\mathrm{C}-\mathrm{O}-\mathrm{C}$ group is indicated at the 
wave number $1093.63 \mathrm{~cm}^{-1}$ [11]. Additionally, as seen in the figure, the FT-IR spectra of banana peel after carbonized and activated using $\mathrm{ZnCl}_{2}$ and microwave undergo some changes in the position and intensity if compared with the initial banana peel spectra. From the figure, it can be seen that the $\mathrm{C}=\mathrm{C}$ group of aromatic compounds was shifting and getting shallower, meaning that the aromatic group decreased after being activated. It is because the lignin compound which contains aromatic group degraded and re-structured into another compound. The wide absorption peak at $577 \mathrm{~cm}^{-1}$ after activation was lost. It is because this peak is $\mathrm{O}-\mathrm{H}$ deformation group in which the group will undergo a change in shape to another compound.

Additionally, as seen in Fig. 4, there was a comparison between FT-IR spectra of activated carbon $\left(\mathrm{AC}_{\mathrm{M}}\right)$ before and after adsorption test. There was a significant change in the absorption peak of $3438.64 \mathrm{~cm}^{-1}$ after adsorption test with the gas emission of motorcycle. This absorption peak indicates the presence of an $\mathrm{O}-\mathrm{H}$ group that allows the presence of water, alcohol, and phenol components. The odds of the O-H group multiply after adsorption was likely due to reaction between hydrocarbons based fuel in motorcycles with the oxygen to produce $\mathrm{CO}_{2}$ and $\mathrm{H}_{2} \mathrm{O}$. The resulting $\mathrm{H}_{2} \mathrm{O}$ might be adsorbed on the activated carbon, and thus increasing the $\mathrm{O}-\mathrm{H}$ group on the activated carbon spectra after adsorption test.

\subsection{Exhaust emission analysis}

The analysis of reduction of $\mathrm{CO}$ and $\mathrm{HC}$ gas in the exhaust emission of motorcycle (Mio 2012, Honda) was carried out by using a gas analyzer instrument, STARGAS 898 (Technotest, Italy). The analysis was divided into 4 parts, which are: 1) direct gas emission measurements (without activated carbon); 2) using carbon/char, before activation; 3) using activated carbon activated by $\mathrm{ZnCl}_{2}$ and microwave $\left(\mathrm{AC}_{\mathrm{M}}\right)$; and 4) using activated carbon activated by $\mathrm{ZnCl}_{2}$ and furnace $\left(\mathrm{AC}_{\mathrm{F}}\right)$. The objective of the analysis is to find out the gas emission levels (especially $\mathrm{CO}$ and $\mathrm{HC}$ ) of various variables tested. The data collection of gas emission analysis was carried out for 8 minutes with constant motor speed of $60 \mathrm{~km} /$ hour. Every minute the results were printed out. The first gas emission analysis results (without using activated carbon) has resulted in $\mathrm{CO}$ emission level of $7.558 \% \mathrm{vol}$ and $\mathrm{HC}$ gas of $470 \mathrm{ppm}$ volume. Whereas, the next analysis results were presented in term of gas $\mathrm{CO}$ and $\mathrm{HC}$ removal efficiency (compared to the first analysis), which are shown in Fig. 5 and Fig. 6 respectively.

As seen in both Figs. 5 and 6, the concentration of gas emissions from the muffler that did not use activated carbon was higher than by using activated carbon. The activation of banana peel based carbon is believed can improve the adsorption of gas $\mathrm{CO}$ and HC. Additionally, the adsorption efficiency of the activated carbon, $\mathrm{AC}_{\mathrm{M}}$ was higher than the char (without activation) and $\mathrm{AC}_{\mathrm{F}}$. The gas $\mathrm{CO}$ emission levels before and after the use of activated carbon $(\mathrm{ACM})$ were $7.558 \%$ and $0.174 \%$ $(\% \mathrm{Vol})$. Whereas, the gas CO emission standard for motorcycle production in 2010 and above was $4.5 \%$, which is below $7.558 \%$.

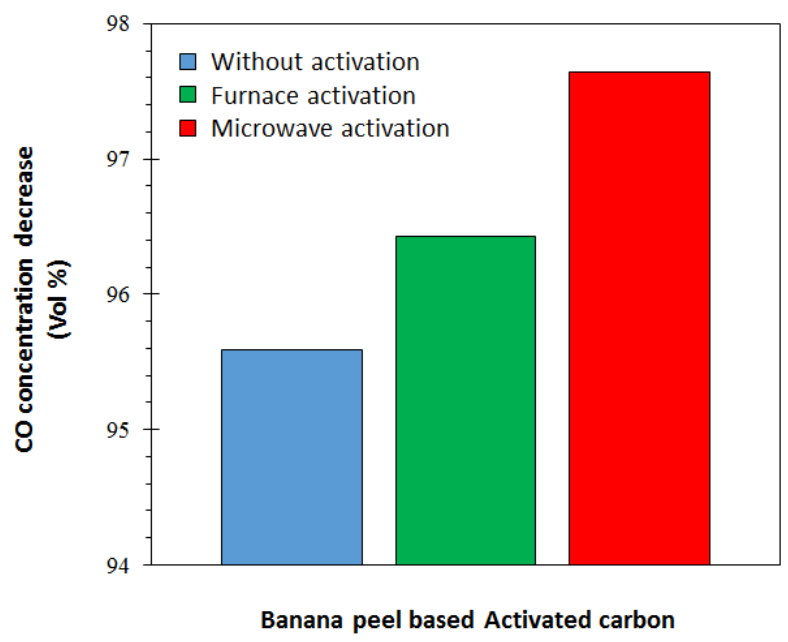

Fig. 5. Gas CO removal efficiency

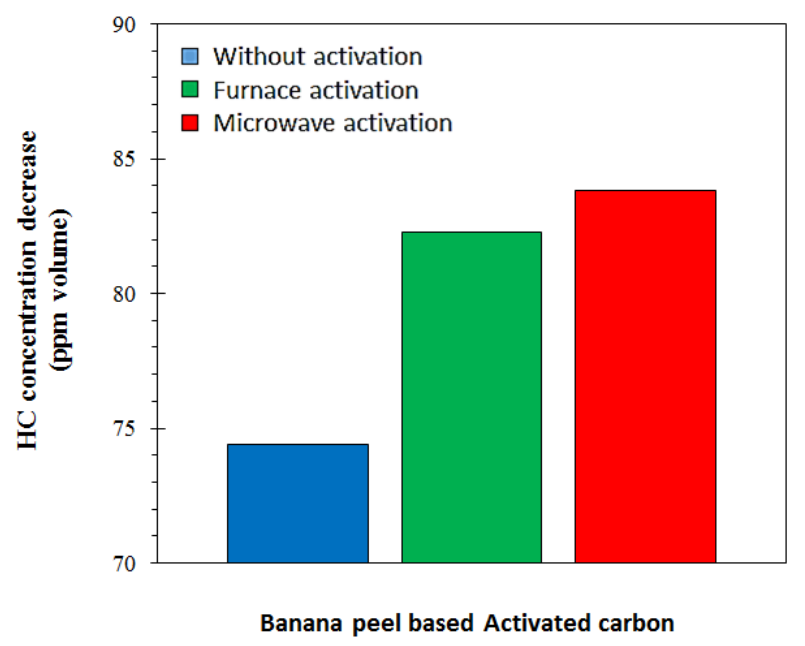

Fig. 6. Gas HC removal efficiency

It can be concluded that the motorcycle being tested without using activated carbon did not meet the gas emission standard set by the government. In other hand, by using activated carbon, the gas $\mathrm{CO}$ emission level met the standard, which is much less than $4.5 \%$. Additionally, the gas $\mathrm{HC}$ emission levels before and after the use of activated carbon $\left(\mathrm{AC}_{\mathrm{M}}\right)$ were $470 \mathrm{ppm}$ and $58 \mathrm{ppm}(\mathrm{ppm}$ Vol.). Whereas, the gas $\mathrm{HC}$ emission standard for motorcycle production in 2010 and above was $2000 \mathrm{ppm}$. This indicates that even without the use of activated carbon, the exhaust emission from motorcycles have met the standard. Nevertheless, by using activated carbon (either $\mathrm{AC}_{\mathrm{M}}$ or $\mathrm{AC}_{\mathrm{F}}$ ), the gas $\mathrm{HC}$ emission level was much less than that without the use activated carbon.

\section{Conclusion}

In the present work, activated carbon was prepared from local banana peel which considered as an agricultural waste without economic value. Three samples of activated carbon were prepared which are: banana peel char/carbon 
(without activation), activated carbon by microwave $\left(\mathrm{AC}_{\mathrm{M}}\right)$, and activated carbon by furnace $\left(\mathrm{AC}_{\mathrm{F}}\right)$. The SEM result showed that the pore of microwave induced $\mathrm{ZnCl}_{2}$ activated carbon $\left(\mathrm{AC}_{\mathrm{M}}\right)$ was larger than the pore of virgin char/carbon and furnace induced $\mathrm{ZnCl}_{2}$ activated carbon $\left(\mathrm{AC}_{\mathrm{F}}\right)$. The FT-IR spectrum of $\mathrm{AC}_{\mathrm{M}}$ showed some peaks at $3408.59 \mathrm{~cm}^{-1}, 1589.25 \mathrm{~cm}^{-1}$, and $1093.63 \mathrm{~cm}^{-1}$. They are assigned to $\mathrm{O}-\mathrm{H}$ stretching, $\mathrm{C}=\mathrm{O}$ stretching, and $\mathrm{C}-\mathrm{OH}$ stretching. Additionally, the adsorption performance of the prepared activation carbon to reduce the pollutants concentration (i.e. $\mathrm{CO}$ and $\mathrm{CH}$ ) from the exhaust gas of motor vehicle was investigated. The results showed that the activated carbon induced by microwave and $\mathrm{ZnCl}_{2}$ activation $\left(\mathrm{AC}_{\mathrm{M}}\right)$ gave the best result. The adsorption or removal efficiency of gas $\mathrm{CO}$ reached approximately $97.64 \%$ vol.

\section{References}

1. O. Pezoti Jr., A.L. Cazetta, I.P.A.F. Souza, K.C. Bedin, A.C. Martins, T.L. Silva and V.C. Almaida, J. Ind. Eng. Chem, 20 (2014) 4401-4407.

2. W. Astuti, R.A. Hermawan, H. Mukti and N.R. Sugiyono, AIP Conf. Proc., 1788 (2017) 030082-1030082-5.

3. J.S. Nazzal, W. Kaminska, B. Michalkiewicz and Z.C. Koren, Industrial Crops and Products, 47 (2013) 153-159.

4. M. Acikyildiz, A. Gurses and S. Karaca, Microporous Mesoporous Mater., 198 (2014) 45-49.

5. W. Astuti, T. Sulistyaningsih and M. Maksiola, Asian J. Chem., 29 (2017) 133-138.

6. L.C.A. Oliveira, E. Pereira, I.R. Guimaraes, A. Vallone, M. Pereira, J.P. Mesquita and K. Sapag, J. Hazard. Mater, 165 (2009) 87-94

7. H. Tibolla, F.M. Pelissari, M.I. Rodrigues and F.C. Menegalli, Industrial Crops and Products, (2016) 111.

8. L. H. Tzong, Chem. Eng. J., 158 (2010) 129-142.

9. D. Liu, J. Taiwan Inst. Chem. Eng., 59 (2016) 563 568.

10. K. Mohanty, D. Das and M.N. Biswas, Chem. Eng. J., 115 (2005) 121-131.

11. W. Astuti, T. Sulistyaningsih and M. Maksiola, Jurnal Teknologi, 79 (2016) 35-42. 